\title{
Chapter 8 \\ The Structure of Leadership Language: \\ Rhetorical and Linguistic Methods \\ for Studying School Improvement
}

\author{
Rebecca Lowenhaupt
}

\subsection{Introduction}

As the field of educational leadership evolves, there has been an increased focus on school-level leaders as architects and implementers of reform efforts. Research has established the importance of these local leaders, emphasizing the ways school leaders can create the conditions and capacity for enacting change (Spillane, 2012). While this research has focused on leadership actions, earlier work reminds us of the often overlooked yet crucial actions that occur in the form of leadership talk, one of the most prevalent and influential forms of leadership practice (Gronn, 1983). Indeed, school leaders use language both to describe and to enact practice, as talk is often the medium through which key actions occur within schools (Lowenhaupt, 2014).

Building theory about the language of school leadership, this chapter considers the frameworks and methodologies used to study the everyday communication strategies leaders use. In so doing, I aim to describe both why and how one might study principal talk. As illustrated through various analyses of discourse in organizational studies (Alvesson \& Kärreman, 2000; Suddaby \& Greenwood, 2005), language is a fundamental feature of social organizations (Gee, 1999; Heracleous \& Barrett, 2001), and the leadership of those organizations (Gronn, 1983; Mehan, 1983). I argue that understanding the role of leadership in school improvement requires deeper study of the form and content of language used to enact reform.

Framing language as action, this chapter explores the methodological implications of attending to leadership language. I consider how research about the ways leaders use language in their daily practice might contribute important insights into how leadership shapes school improvement. Understanding how language is used as

R. Lowenhaupt $(\bowtie)$

Boston College, Newton, MA, USA

e-mail: rebecca.lowenhaupt@bc.edu

A. Oude Groote Beverborg et al. (eds.), Concept and Design Developments in School Improvement Research, Accountability and Educational Improvement, https://doi.org/10.1007/978-3-030-69345-9_8 
a tool for enacting reform can shed light on the microprocesses of school improvement.

After first considering the role of language in principal practice, I then discuss the methods associated with linguistic analyses and explore how those methods might be used in the study of school leadership. I then share examples from my previous work, before concluding with a discussion of implications for future work. Overall, this chapter aims to demonstrate how language is a crucial feature of leadership practice, and one, which must not be neglected in research about school effectiveness and improvement.

\subsection{School Leadership and School Improvement}

In the last few decades, policymakers at federal, state, and district levels have increasingly looked to school principals to implement school-level reforms (Darling-Hammond, LaPointe, Meyerson, \& Orr, 2007; Horng, Klasik, \& Loeb, 2010; Spillane \& Lee, 2014). Improvement efforts focused on standardizing curricula, enacting accountability measures and developing teacher evaluation systems all depend on the work of principals to implement them in their schools (Kraft \& Gilmour, 2016; Lowenhaupt \& McNeill, 2019). While previous conceptions of the principal role focused primarily on managerial tasks, along with buffering teacher autonomy (Deal \& Celotti, 1980; Firestone, 1985; Firestone \& Wilson, 1985), principals are now asked to lead efforts to develop professional communities, support instructional improvement, and bridge classrooms, family, and community (Lowenhaupt, 2014; Rallis \& Goldring, 2000).

In response, a focus on principal practice has emerged in recent research with efforts to understand how specific practices influence school effectiveness (Camburn, Spillane, \& Sebastian, 2010; Grissom \& Loeb, 2011; Horng et al., 2010; Klar \& Brewer, 2013). Although many of these studies are quantitative, various qualitative studies also contribute to our understanding of school principals as they navigate a range of responsibilities. In the tradition of longstanding in-depth work about the role (Dillard, 1995; Gronn, 1983; Peterson, 1977; Wolcott, 1973), these studies develop portraits about the daily work and practice of school leaders in an increasingly complex reform context (Browne-Ferrigno, 2003; Khalifa, 2012; Spillane \& Lee, 2014; Lowenhaupt \& McNeill, 2019; Spillane \& Lowenhaupt, 2019). Employing a range of methodologies, from surveys and administrative logs to ethnographic observations and interviews, these studies highlight the various roles and complexities these school-level leaders navigate in the context of improvement efforts.

Importantly, this research elaborates on the diversity of tasks principals engage in throughout their days, as they enact their various responsibilities. As instructional leaders (Goldring, Huff, May, \& Camburn, 2008; Hallinger, 2005), meaning-makers (Bolman \& Deal, 2003; Dillard, 1995; Peterson, 1977), coalition-builders (Lortie, 2009), managers (Goldring et al., 2008; Horng et al., 2010), and community leaders 
(Dillard, 1995; Khalifa, 2012; Peterson, 1977), they work with stakeholders both within and outside of their schools to ensure school effectiveness. As such, interactions are a crucial part of their work via building strong relationships, bringing stakeholders together, and mediating conflict (Peterson \& Kelley, 2002; Rallis \& Goldring, 2000). All these responsibilities depend on the use of language to communicate a vision, negotiate competing demands, and promote reforms. Yet too often, research treats language as the medium for action without attending to the language as an integral part of the practice itself (Lowenhaupt, 2014).

\subsection{Leadership Language as Action}

Although a robust body of research has emerged related to these new school leadership practices, only a handful of scholars have turned their attention explicitly to the language used to enact them. These scholars have argued for the need for further research about the discourse of leadership (Lowenhaupt, 2014; Riehl, 2000). Recognizing that "talk is the work" (Gronn, 1983), a handful of scholars have employed discourse and linguistic analytic methodologies to explore how leaders use language as practice.

Some researchers have focused on the linguistic strategies principals develop to persuade teachers to shift their practice (Gronn, 1983; Lowenhaupt, 2014), while others have explored how language is central to the symbolic meaning-making principals engage in to develop school culture (Deal \& Peterson, 1999). By shaping communication, spoken or written, formal or informal, to argue for particular outcomes, principals draw on a range of rhetorical and linguistic repertoires to enact their leadership. As such, language ought to be viewed as a practice, which leaders can and often do purposefully and strategically employ in relation to others.

Importantly, this leadership language cannot be viewed as one-directional or limited to an individual leader. Theories of distributed leadership have emphasized that leadership is shared across individuals and in relationship between leaders and followers (Leithwood, Harris, \& Hopkins, 2008; Spillane, 2012). In order to understand how language functions within the context of interactions, scholars need to move beyond the language of individual leaders to study the negotiations and discussion that occur in conversations among various stakeholders (Gronn, 1983; Mehan, 1983; Riehl, 1998). An important focus for these interaction analyses is the linguistic processes that play out in meetings and the ways in which language influences and informs the change process among administrators and teachers (e.g. Riehl, 1998). In another example, Mehan (1983) looked at the administrative process of Special Education identification and the form and content of discourse in meetings among administrators, staff, and families. In both cases, these studies identified features of language that influenced outcomes for students and educators. Taken together, these various studies point to the need for further study of everyday language that considers the levers of change particular leaders employ through their talk. 
While some of these interactions are public, high-stakes forms of talk, it is important to highlight that leadership language occurs in both informal and formal settings. Although principals are called on to give speeches, write public statements, and interact during public forums, they also engage in conversation throughout their day-to-day work. This prior scholarship reminds us that this talk, particularly in the context of reform efforts, is never neutral. Indeed, these various interactions work as a form of persuasion with political implications, as well as implications for school effectiveness.

Turning the lens on the linguistic form and content of these interactions reminds us that language both describes and creates actions. As such, language is both a means for enacting practice, as well as a practice in and of itself. Empirical study of leadership language requires discourse analyses focused on both the form and content of that language in distinct contexts in order to uncover exactly how principals use language toward school effectiveness (Riehl, 2000). A linguistic turn in the study of school leadership requires a shift in methodologies to uncover the ways in which language manifests itself as action. I turn to a discussion on methodology next.

\subsection{Language in Organizations}

Educational leadership is not the only field to seek a linguistic turn in social science research. Across the social sciences and within education, various forms of discourse analyses have developed as a methodology for interpreting language practices within complex socio-cultural contexts (Gee, 1999). In the field of organizational studies, scholars have also drawn on studies of discourse to understand how everyday language shapes the nature of those organizations (Alvesson \& Kärreman, 2000; Heracleous \& Barrett, 2001; Watson, 1995). Across these fields, research has drawn attention to the ways in which various forms of language are used to, "continually and actively build and rebuild our world" (Gee, 1999, p. 11).

Language in organizations takes on many forms. In addition to formal written policies, which instantiate structures and systems, language also manifests itself through informal everyday interactions which constitute the social nature of organizations (Alvesson \& Kärreman, 2000; Hallett, Harger, \& Eder, 2009). During meetings, hallway conversations, and gossip in the workplace, people use language to share opinions, interpret realities, and shape practice (Hallett et al., 2009). For school leaders, talk is a central way by which formal policies are implemented in schools (Lowenhaupt, Spillane, \& Hallett, 2016). The proliferation of digital communications through email, social media, and text messaging have further expanded the linguistic repertoires of the workplace.

Taken together, this complex ecosystem of language use within organizations provides ample fodder to researchers focused on investigating how language shapes leadership practice in schools. Drawing on the tools of discourse analysis, researchers might examine how the form and content of particular features of leadership 
language influence improvement. In the context of school improvement, where leaders work to enact deep reform, I argue that rhetoric, or the language of persuasion, is a particularly fruitful area of inquiry, as I discuss in more detail next.

\subsection{Rhetorical Analyses}

To examine the everyday leadership language that is used in school improvement, rhetorical analysis provides the methodological tools to understand how persuasion works in the context of school improvement. Within a reform context, school leaders must establish the rationale for change and engage both staff and community members in new activities. One key mechanism for this is talk, and more specifically, persuasion. For leaders within these organizations, persuasion is a key, yet often implicit, feature of the social dynamics that lead to (or hinder) organizational change (Suddaby \& Greenwood, 2005). Rhetoric is defined as the linguistic features of persuasion (Corbett \& Connors, 1999). Within organizations, the role of rhetoric is one of the least well understood forms of coordination and control (Stone, 1997).

Recent work in organizational studies has drawn on rhetorical analyses to develop an understanding of how linguistic patterns influence the structure of organizations and lead to institutional change (Alvesson \& Kärreman, 2000; Brown, Ainsworth, \& Grant, 2012; Mouton, Just, \& Gabrielsen, 2012; Suddaby \& Greenwood, 2005). Similarly, the field of educational leadership might develop methods for rhetorical analyses to explore one form of language particularly relevant to unpacking leadership practice for school improvement.

The study of rhetoric focuses on both the form and content of language to reveal the linguistic structures of persuasion. Defined as the language used to persuade an audience, classical rhetoric continues to undergird the structure of our everyday language today (Corbett \& Connors, 1999). As a method used in organizational studies, rhetorical analyses uncover implicit structures of persuasive language to demonstrate the, "recurrent patterns of interests, goals, and shared assumptions that become embedded in persuasive texts" (Suddaby \& Greenwood, 2005, p. 49). While some focus on written text, others analyze spoken language to examine everyday interactions integral to the function of organizations (Gill \& Whedbee, 1997).

Rhetorical analyses rely on strategies of textual analysis to explore linguistic features and patterns. As with other types of thematic qualitative analyses, systematic coding of text allows for the identification of forms and features of rhetoric. Working with transcripts, written communications, or other text, one can make use of various qualitative coding software to identify, select, and analyze particular linguistic segments that play a role in persuasion. By looking systematically at particular elements of language, one can uncover the underlying patterns and features of rhetoric. In particular, coding focused on audience, form, and content comprises analyses of rhetorical features.

One fundamental aspect of rhetoric is an emphasis on audience (Corbett \& Connors, 1999). Drawing on various rhetorical forms, the speaker shapes rhetoric to 
influence specific audience members in particular ways. Although not always purposeful or strategic, speakers draw on various linguistic forms to persuade depending on the particular orientation of the audience (Corbett \& Connors, 1999). In terms of school leadership, this means using distinct rhetorical arguments depending on the various stakeholders involved, whether families, staff, community members, or students. Accordingly, rhetorical analyses take into consideration the social dynamics of the speaker-audience relationship and explore differences in argumentation as the audience shifts. This emphasis is in line with distributed leadership theory, which urges researchers to look at the interactions among leaders and followers as an interactive, socially constructed perspective on leadership (Spillane, 2012). Bringing rhetoric and leadership together, then, encourages research that looks at the language of interactions among leaders and various stakeholders. Taking this into account, textual analysis can attend to differences among stakeholders and compare varying uses of rhetoric based on audience.

In addition to a focus on audience, classical rhetoric also places form at the heart of understanding persuasion. Rhetorical analysis often begins with an examination of three primary forms central to argumentation, namely logos, ethos, and pathos (Corbett \& Connors, 1999). The rational appeal, logos, uses reasons and justifications as an appeal to an audience's intellect (Suddaby \& Greenwood, 2005). This form of appeal may vary by audience, as what seems logical to one group may be adapted for another group. Regardless, the key basis of persuasion for logos is reasoning and logic. In the context of school improvement, leaders might provide rational arguments for change and emphasize the need for improvement based on evidence, such as student achievement. Another form of argument, ethos, draws on the underlying ethics or values held by a particular organization. As such, the speaker makes an ethical claim that the argument aligns well with the values and orientation of the audience. While such appeals are often implicit throughout the interaction, rhetoric is considered ethos when it occurs as a specific and explicit argument used to establish the relatability and legitimacy of the speaker in espousing similar ethical values (Corbett \& Connors, 1999). Often, leaders rely on the ethos of care for students or a sense of social obligation to motivate improvement efforts. Finally, the emotional appeal, or pathos, draws on the affective side of the argument to persuade. Arguably the most complex form, pathos is considered an appeal to the imagination and often takes the form of evocative storytelling or sharing emotionally charged examples, an appeal to the heartstrings (Corbett \& Connors, 1999). School leaders might share anecdotes about student successes or hardships to motivate and inspire improvement.

While there are other structural features identified in classical rhetoric, these three forms are embedded throughout persuasive language and provide a meaningful frame for rhetorical analyses. By considering the rhetorical form for each segment of text and exploring the pattern of use across multiple forms, one can uncover the underlying structure of persuasion leaders use to try to convince others to enact improvement. Importantly, forms may be interwoven or occur independently throughout both formal and informal persuasion. Sometimes, these forms may co-occur, as leaders simultaneously draw on multiple forms of appeal. The ways in 
which they are used and the relative affordances of each vary according to the speaker-audience relationship and the context of the argument (Aristotle, 1992).

While both audience and form are crucial areas of focus for rhetorical analyses, the language of persuasion also relies on content specific to the argument at hand. In the case of school leaders, that content is developed based on the particular initiatives and reforms leaders seek to enact for school improvement. Yet, the content also builds on longstanding values and professional norms in the field of education, as well as the particular school and community cultures in which leaders work. In other words, the implementation of new policies does not occur in a vacuum, but rather builds on and intersects with existing practices, beliefs, and knowledge (Spillane, 2012). As such, for persuasion to work, leaders must take up and navigate these existing socio-cultural aspects of their context. The content of rhetoric can serve to illuminate how new initiatives link to current context (Lowenhaupt et al., 2016). In other words, rhetorical content can construct a bridge between longstanding ways of thinking about the meaning and purpose of the work and new practices for school improvement.

Bringing together these three elements of audience, form, and content, rhetorical analyses can help identify meaningful patterns of persuasion and reveal how leadership language shapes school improvement. To conduct such analyses, identifying meaningful instances of language use and transforming it into transcripts or text can support a systematic coding process. Audio or video-recording, email communications, or other written artifacts can thus become data sources. Meeting transcripts are a particularly promising source, as leaders must often present the case of their improvement efforts to various audiences. By creating a coding structure and applying a systematic process through a qualitative coding software, such as Nvivo or Dedoose, researchers can enact rigorous rhetorical analyses. Using a combination of deductive and inductive approaches can make visible both the inherent linguistic structure and the shape of the argument. For example, applying a priori codes for logos, ethos, and pathos reveals rhetorical forms and sequences. At the same time, emergent, thematic coding for content can reveal the key arguments leaders use to persuade.

The linguistic turn in organizational studies provides fruitful lessons for the study of school improvement, and more specifically, the role of leadership in enacting reform. Drawing on various tools of discourse analyses, a focus on language can provide opportunities to learn about and subsequently shape the discursive practice of leadership in schools. Rhetorical analyses provide one possible framework with which to develop research methods for examining the linguistic features of leadership. Given the need for deeper understanding of how principals use language to both describe and enact reforms, I argue that the study of rhetoric holds substantial promise as a methodological approach to understanding leadership practice, particularly within the context of school improvement and change. To illustrate the potential of this approach, I next turn to an example of one study, which applied classical rhetoric to the analysis of leadership language. 


\subsection{Rhetorical Form and Principal Talk: An Example}

Through a series of rhetorical analyses of one principal's language in various meetings during a year of school improvement, my collaborators and I investigated the rhetorical forms and content used to enact substantial reform in one urban public school (See Lowenhaupt, 2014; Lowenhaupt et al., 2016, for the complete studies). Working with data from a larger study of school reform led by Dr. James Spillane at Northwestern University and along with Dr. Timothy Hallett at Indiana University, who conducted the initial fieldwork, our team analyzed the rhetoric used by Mrs. Kox, an urban elementary school principal, to advocate for reform.

As a new principal, she was charged with implementing accountability measures focused on increasing student achievement. With support from the district, she increased classroom visits, encouraged standardization across classrooms, and conducted an audit of instruction focused on achievement measures. As she implemented these reforms, researchers observed and recorded many of her interactions with teachers, families, and other administrators as part of an in-depth ethnographic case study.

\subsubsection{Methods}

Analyzing 14 transcripts from two types of administrative meetings, we documented the microprocesses of organizational talk in meetings, key sites for organizational work (Riehl, 1998). External stakeholders were engaged through School Council meetings, where locally elected community members discussed initiatives with the principal. Empowered to represent the best interests of the community and overseeing the management of the school, this group was also responsible for evaluating the principal. Non-elected members of the community were also often present at these public meetings, where recent initiatives, policy reforms, and school change were discussed. Internal stakeholders participated in similar conversations in closed Leadership Team meetings, where select teachers and staff engaged in conversations about how to enact reforms.

We engaged in a series of textual analyses to surface the form and content of Mrs. Kox's rhetoric and explored how these aspects of rhetoric differed by audience. Taken together, these analyses presented insight into how to put into practice a rhetorical analysis of principal talk, as well as some considerations for this approach. Using qualitative coding software, Nvivo, we initiated the analysis by creating discrete segments of principal rhetoric ranging from a few words to full sentences (Suddaby \& Greenwood, 2005). Decisions about where a particular 'utterance' began and ended were made with rhetorical form in mind, but drew on the context of the meeting as well (Gee, 1999; Goffman, 1981). For example, in one meeting, Mrs. Kox stated, "We need to define the curriculum because there is a need for consistency throughout the grades." In this case, the utterance was defined as a 
complete sentence because it constituted a rhetorical unit with a claim, the need to define the curriculum, along with a rationale for that claim, the need for consistency. In other instances, one sentence consisted of multiple claims, in which case we coded clauses within sentences as discrete utterances. And in other instances, although rare, we coded multiple sentences as one utterance if it consisted of one rhetorical idea.

In this way, even at the early stages of analyses, the rhetorical framework influenced the process. Recognizing the importance of counter-argument as an influence on the persuasive process (Goffman, 1981; Symon, 2005), the analytic decision to focus exclusively on principal talk was primarily logistical, based on the need to focus on a manageable subset of utterances for analysis. Ultimately and across all 14 meeting transcripts, 650 utterances were coded as instances of principal rhetoric. We accounted for interaction through iterative analyses that looked at particular utterances in the broader context of discourse as well.

Once these utterances were identified, we worked as a research team on an iterative coding process. We conducted four distinct stages of analyses to examine form, content, audience, and sequences. During the first stage of analysis, two researchers independently coded approximately $20 \%$ of the total set of utterances according to a deductive, closed coding scheme of the three rhetorical forms, logos, ethos, and pathos (Corbett \& Connors, 1999). We also employed a code for 'other' that took into account utterances that were difficult to categorize and which we ultimately determined to fit within one of the three forms. Importantly, we did allow for coding in multiple categories. After calculating interrater reliability for each code, we then engaged in an arbitration process, discussing our rationale on how we coded each utterance and resolving any disagreements. This process led to refining definitions of these forms, identifying examples of particular forms, and creating a coding manual that clearly explicated these features of each code (See Table 8.1). We then applied the coding scheme to the remaining utterances.

A second stage of analysis aimed to identify the content of the arguments through an inductive, open coding process within each form. This second iteration yielded content-based codes that described the general themes that were treated with the various rhetorical forms. In this way, we aimed to capture both what the principal discussed through rhetoric, as well as to explore the deeper discourses she tapped into through her persuasive language (Alvesson \& Kärreman, 2000; Gee, 1999). For example, her use of ethos tended to rely on either an effort to assert her own legitimacy to teachers by referring to her prior experiences as an educator or an appeal to the ethical obligation of doing 'what's best for kids'. This appeal to serving children is a longstanding, professional commitment among educators and seeks to persuade others by reminding them of this commitment. During this stage of analysis, we employed a similar, collaborative process, while working together to determine an initial set of thematic codes, applied and refined them through arbitration, and ultimately developed a set of sub-codes within each form, as depicted in Table 8.1.

Once the entire set of utterances was coded for form and sub-coded for content, we embarked on a third stage of analyses to explore the underlying structure of principal rhetoric as it related to audience. We used inferential statistics, specifically 
Table 8.1 Coding structure

\begin{tabular}{|c|c|c|c|}
\hline Form & Definition & Examples & $\begin{array}{l}\text { Content } \\
\text { subcodes }\end{array}$ \\
\hline \multirow{4}{*}{$\begin{array}{l}\text { Logos: } \\
\text { rational } \\
\text { appeal }\end{array}$} & \multirow{4}{*}{$\begin{array}{l}\text { Through the use of justifications, } \\
\text { examples, and evidence, the rational } \\
\text { appeal attempts to persuade through the } \\
\text { use of (or appearance of) logic (Corbett } \\
\& \text { Connors, 1999). }\end{array}$} & \multirow{3}{*}{$\begin{array}{l}\text { "We need to define the } \\
\text { curriculum because } \\
\text { there is a need for } \\
\text { consistency throughout } \\
\text { the grades." }\end{array}$} & $\begin{array}{l}\text { Professional } \\
\text { knowledge }\end{array}$ \\
\hline & & & $\begin{array}{l}\text { Common } \\
\text { sense }\end{array}$ \\
\hline & & & \multirow[b]{2}{*}{$\begin{array}{l}\text { Appeal to } \\
\text { authority }\end{array}$} \\
\hline & & $\begin{array}{l}\text { "There are always } \\
\text { going to be some } \\
\text { standards and there will } \\
\text { always be some } \\
\text { guidelines." }\end{array}$ & \\
\hline \multirow[t]{2}{*}{$\begin{array}{l}\text { Ethos: } \\
\text { ethical } \\
\text { appeal }\end{array}$} & \multirow{2}{*}{$\begin{array}{l}\text { By which the speaker convinces the } \\
\text { audience by his or her words that he/she } \\
\text { is of high moral character. The ethical } \\
\text { appeal, "must display a respect for the } \\
\text { commonly acknowledged virtues and an } \\
\text { adamant integrity" (Corbett \& Connors, } \\
\text { 1999, p.73) }\end{array}$} & $\begin{array}{l}\text { "When I came to this } \\
\text { school, I established a } \\
\text { guideline." }\end{array}$ & $\begin{array}{l}\text { Morality } \\
\text { related to } \\
\text { children }\end{array}$ \\
\hline & & $\begin{array}{l}\text { "The bottom line here } \\
\text { is that we're providing } \\
\text { services to the } \\
\text { children." }\end{array}$ & $\begin{array}{l}\text { Legitimacy as } \\
\text { a leader }\end{array}$ \\
\hline \multirow{5}{*}{$\begin{array}{l}\text { Pathos: } \\
\text { emotional } \\
\text { appeal }\end{array}$} & \multirow{5}{*}{$\begin{array}{l}\text { The emotional appeal persuades by } \\
\text { engaging the emotions of the audience, } \\
\text { an appeal to the imagination through } \\
\text { illustrative stories and the use of } \\
\text { exaggerated, emotional language. }\end{array}$} & \multirow{5}{*}{$\begin{array}{l}\text { "It's really } \\
\text { marvellous...there's a } \\
\text { lot of wonderful things } \\
\text { happening in the } \\
\text { school." }\end{array}$} & Evoking pity \\
\hline & & & $\begin{array}{l}\text { Showing } \\
\text { empathy }\end{array}$ \\
\hline & & & Story \\
\hline & & & Humor \\
\hline & & & Enthusiasm \\
\hline
\end{tabular}

chi-square analyses, to compare findings by audience by comparing Kox's rhetoric across meeting types. Taken together, these three stages of analysis facilitated both the study of the form and content of a principal's use of rhetoric, as well as the interpretation of how this rhetoric varied by audience.

In a fourth follow-up analysis, we investigated what emerged as an important feature of principal talk, the linking of multiple utterances working in concert to create an integrated, bridging form of persuasion we called 'accountability talk' (Lowenhaupt et al., 2016). Through analysis of rhetorical sequences, we demonstrated how Mrs. Kox relied on multiple forms together, primarily logos but linking logos with ethos and pathos, to bridge her new initiatives and their rationale with longstanding commitments in the field. In this analysis of sequences, we moved between discrete utterances, groups of utterances, and the broader meeting context to identify how this accountability talk was constructed. At all stages of this process, we articulated and followed a set of systematic steps which allowed us to uncover the underlying structures that undergirded the persuasive language one principal used in the reform context. 


\subsubsection{Findings}

Findings from these analyses demonstrated that the principal used multiple forms of rhetoric to link accountability initiatives to existing norms, relying primarily on rational logics (logos), but also incorporating ethical (ethos) and emotional (pathos) arguments to solicit support for reforms (Lowenhaupt, 2014). Her reliance on logos illustrated the importance of reason and logic, but this was not enough to persuade. At the same time that her improvement efforts centered on logos, she also drew on ethical and emotional appeals, particularly with teachers, who were most directly impacted by her initiatives. Further analyses illustrated how these forms were woven together into rhetorical sequences that served to integrate longstanding norms with emerging policy pressures into a type of speech we termed, "accountability talk" (Lowenhaupt et al., 2016).

Focusing on rhetorical structure not only reveals how language is used to persuade others to engage in school improvement, but also can play an active, key role in improvement efforts. In the example presented above, the principal relied on rhetoric to promote support for aspects of improvement, such as accountability. Her use of rhetorical form established certain ideas as logical and asserted the importance of logic in the design of school improvement. She anchored this in treasured values of schooling by appealing to a sense of social obligation. The very structure of her rhetoric reminds both internal and external stakeholders that logic alone is not the motivation for improvement. As such, rhetoric can be viewed as a tool or strategy for improvement.

\subsubsection{Limitations}

This endeavour was limited in several ways, which are important to weigh when conducting any form of linguistic analyses. First, linguistic analyses provide important insight into the microprocesses underlying language, but present logistical challenges related to scope and breadth. This is an inherent consideration when navigating large amounts of language across contexts. Because this study focused on one case only, it is difficult to make generalizations about the use of rhetoric more broadly. By narrowing the scope to participation in particular meetings, the study did not explore more informal forms of interaction that might have yielded different insights into the principal's use of persuasion. As such, this study and other studies are often limited by issues of accessibility and feasibility.

Second, methodologically, the study did not take a systematic approach to exploring the co-construction of meaning through argument and counter-argument that occurs through interaction. Understanding leadership as a distributed process across actors (Spillane, 2012) raises concerns about the approach that focused narrowly on an individual's language use, with limited consideration of the influence of interaction. Exploring the possibilities of other forms of discourse analysis that take 
interaction into account might provide a different form of insight into the negotiated enactment of school improvement among leaders, staff, and others. While rhetorical analyses can provide important insights into the role of persuasion, conversation analyses might help unpack the role of interaction and discussion in creating new meanings, fostering collaboration, and building consensus for improvement efforts.

Third, the rhetorical analyses conducted here drew on informal and unplanned interactions occurring within meetings. Although the meetings provided a particular, formal context for interaction, the analyzed utterances were not necessarily premeditated. Thus, researchers recognized the implicit and likely unplanned nature of leadership language here, limiting conclusions about the intentionality of the principal's use of rhetoric. This is an inherent feature of studying language in everyday practice, as opposed to more formal and prepared speech acts, such as presentations and written communications (Heracleous \& Barrett, 2001). Although I have framed an argument here for the importance of examining both formal and informal linguistic structures, we need to interpret findings as they relate to the nature of the language analyzed.

Keeping these limitations in mind, I would argue that the approach outlined in detail above provides a useful model for how one might uncover, learn from, and shape the underlying rhetorical forms at play in the context of school improvement. Such analyses allow us to explore the often invisible mechanisms of language that influence the day-to-day realities of social organizations. In particular, they shine a light on the role of persuasion in leadership practice and present an opportunity for further research that builds on an understanding of how rhetorical form and content might be used to promote and develop school improvement.

\subsection{Methodological Considerations}

As the example discussed above demonstrates, linguistic analyses provide substantial opportunities for learning about leadership language in the context of school improvement. Even so, there are some important considerations worth exploring when thinking about these opportunities. The examples from our work draw on analyses of transcripts generated from recordings of interactions in meetings focused on individual school leaders, must be interpreted through a set of limitations that likely impacts most studies taking a similar approach. As with all research methodologies, discourse analyses applied to leadership are bounded by some practical considerations, which influence the feasibility of the work.

For example, issues of access are not inconsequential to the study of leadership language, particularly given that some of the most important moments of leadership practice occur through one-on-one interactions with staff, students, and families. These interactions are often sensitive in nature and extremely private. Researchers are unlikely to gain access to these one-on-one interactions, let alone have opportunities to digitally record such meetings for detailed analysis. As such, research on leadership language runs the risk of focusing on a narrow slice of language that is 
more easily obtained, such as public communications and formal meetings. I do not intend to negate the value of linguistic analyses of these practices, but rather highlight the challenges of collecting the full repertoire of interactions relevant to understanding how leaders use language to influence practice and work toward school improvement.

Furthermore, as discussed above, it is often unfeasible to conduct large-scale studies of microprocesses of interactions. This limits the possibilities for generalizability and runs the risk of leading to a series of disjointed studies, which cannot provide wide-ranging applicability to leadership across distinct contexts. The potential to batch process larger sets of text segments or utterances continues to expand as new software technologies emerge. Even so, the sheer volume of language in practice requires carefully constructed samples focused on crafting a meaningful sample across leaders. Again, I want to be clear that there is great value to in-depth analyses of individual cases, which can illuminate undergirding structures of language use within particular contexts. I raise this consideration in order to emphasize the importance of both case selection and collaboration across researchers to compile comparable data and facilitate cross-case analyses at a larger scale.

Mixed-methods approaches also offer great potential for leveraging linguistic analyses for learning about leadership. School improvement efforts rely on complex processes occurring across organizations, and understanding them requires more than one approach to research. Often, researchers rely on survey or interview methods to provide insight into how stakeholders perceive reforms. It is more difficult to document changes to practice itself, but building on ethnographic observation, logs, and other forms of documentation have been used to that end. As discussed here, linguistic analyses offer one way to understand the mechanisms by which these changes to practice occur and therefore provide insight into how leaders actually enact shifts in both practice and perceptions. Mixed-methods approaches to studying leadership have become more widespread, as researchers bring together quantitative approaches to provide breadth with more qualitative methods to ensure depth (Tashakkori \& Teddlie, 2010). Often, however, even these efforts to provide a more holistic understanding of improvement fail to account directly for the role of language, viewing language as a vehicle or medium for practice rather than an aspect of practice itself. By drawing on multiple methods to understand school improvement and incorporating rhetorical analyses, researchers will be able to better understand the relations between leadership language, educators' perspectives, and actual shifts in practice.

Considerations of feasibility, access, and generalizability are all important to future researchers committed to a linguistic turn in the study of school leadership and effectiveness. Building on a growing body of research across the fields of organization studies and education, future scholarship might leverage new analytic tools alongside longstanding linguistic methods to unpack the various ways in which language, in both formal and informal interactions, shapes the daily practices of school leaders and their staff. Through an expanding set of such studies, a collaborative, meta-analytic approach might generate opportunities for sharing across studies and the development of insight across leadership contexts and linguistic practices. 


\subsection{Implications for Practice}

As shown above, various forms of linguistic analyses, such as rhetorical analyses, can be used to help researchers develop an understanding of how language informs, shapes and creates daily practices within schools. But the value of employing such methodologies does not end with researchers. By turning the lens on the everyday interactions that comprise our social organizations, we uncover the often invisible ways work gets done. This is important because, "the routines we practice most, and the interactions we repeatedly engage in are so familiar that we no longer pay attention to them" (Copland \& Creese, 2015, p. 13). School leaders themselves have much to gain from examining their own language use and considering the implicit forms of their language within their schools and communities.

Given the context of reform in the United States, where I work, the skills of rhetoric have become all the more important to school leaders in recent years. With high-stakes accountability systems impacting schools and systems of schools, leaders play an increasingly important role in competing for resources, marketing their schools, and navigating the various conflicts that arise in a high-pressure environment (Lowenhaupt, 2014). At the same time, they are responsible for establishing a vision anchored in the professional ethos of the educational field and ensuring that they provide safe, nurturing spaces for students to inhabit (Frick, 2011). As illustrated above, leadership language has the potential to bridge these enduring norms and commitments of educators with new innovations and practices associated with school improvement. However, this is complex work, and as Gronn (1983) reminds us, talk is the work in which leaders need to engage.

Yet, as I have learned from engaging in fieldwork and working directly with current school leaders, many educational leaders do not apply a purposeful and strategic approach to much of their communication. In feedback they offer teachers, in the management of various meetings, and in day-to-day encounters in the hallway, leaders often focus on the content, rather than on the delivery of their messages. Leadership training programs and professional development opportunities might develop explicit opportunities to learn about linguistic concepts, forms of rhetoric, and a strategy for language use as it relates to supporting school improvement. By considering language as an explicit and core aspect of practice, aspiring and practicing school leaders will have an opportunity to shift their understanding towards incorporating a more purposeful approach to language use in their daily practice.

Throughout this chapter, I have sought to establish the need to leverage research methodologies that facilitate the examination of linguistic features of everyday leadership practices. Although language is a central aspect of leadership, it is often overlooked as simply the implicit medium for action. I have argued here that language use is in fact an explicit and crucial action in and of itself, and one deserving more careful attention, both as a focus for researchers and as an area of development for aspiring and practicing leaders. 


\section{References}

Alvesson, M., \& Kärreman, D. (2000). Taking the linguistic turn in organizational research: Challenges, responses, consequences. Journal of Applied Behavior Science, 36(2), 136-158.

Aristotle. (1992). The art of rhetoric. London, UK: Penguin Classics.

Bolman, L. G., \& Deal, T. E. (2003). Reframing organizations: Artistry, choice, and leadership. San Francisco, CA: Jossey-Bass.

Brown, A. D., Ainsworth, S., \& Grant, D. (2012). The rhetoric of institutional change. Organization Studies, 33(3), 297-321.

Browne-Ferrigno, T. (2003). Becoming a principal: Role conception, initial socialization, roleidentity transformation, purposeful engagement. Educational Administration Quarterly, 39(4), 468-503.

Camburn, E. M., Spillane, J. P., \& Sebastian, J. (2010). Assessing the utility of a daily log for measuring principal leadership practice. Educational Administration Quarterly, 46(5), 707-737.

Copland, F., \& Creese, A. (2015). Linguistic ethnography: Collecting, analysing and presenting data. Beverly Hills, CA: Sage.

Corbett, E. P. J., \& Connors, R. J. (1999). Classical rhetoric for the modern student (4th ed.). New York, NY: Oxford University Press.

Darling-Hammond, L., LaPointe, M., Meyerson, D., \& Orr, M. T. (2007). Preparing school leaders for a changing world: Lessons from exemplary leadership development programs. School leadership study. Executive summary. Palo Alto, CA: Stanford Educational Leadership Institute.

Deal, T. E., \& Celotti, L. D. (1980). How much influence do (and can) educational administrators have on classrooms? The Phi Delta Kappan, 61(7), 471-473.

Deal, T. E., \& Peterson, K. D. (1999). Shaping school culture: The heart of leadership. San Francisco, CA: Jossey-Bass.

Dillard, C. B. (1995). Leading with her life: An African American feminist (re) interpretation of leadership for an urban high school principal. Educational Administration Quarterly, 31(4), 539-563.

Firestone, W. A. (1985). The study of loose coupling: Problems, progress, and prospects. In A. Kerckhoff (Ed.), Research in sociology of education and socialization (Vol. 5, pp. 3-30). Greenwich, CT: JAI Press.

Firestone, W. A., \& Wilson, B. L. (1985). Using bureaucratic and cultural linkages to improve instruction: The principal's contribution. Educational Administration Quarterly, 21(2), 7-30.

Frick, W. C. (2011). Practicing a professional ethic: Leading for students' best interests. American Journal of Education, 117(4), 527-562.

Gee, J. P. (1999). An introduction to discourse analysis: Theory and method. London, UK: Routledge.

Gill, A. M., \& Whedbee, K. (1997). Rhetoric. In T. A. van Dijk (Ed.), Discourse studies: A multidisciplinary introduction (Vol. 1, pp. 157-183). Beverly Hills, CA: Sage.

Goffman, E. (1981). Forms of talk. Philadelphia, PA: University of Pennsylvania Press.

Goldring, E., Huff, J., May, H., \& Camburn, E. (2008). School context and individual characteristics: What influences principal practice? Journal of Educational Administration, 46(3), 332-352.

Grissom, J. A., \& Loeb, S. (2011). Triangulating principal effectiveness: How perspectives of parents, teachers, and assistant principals identify the central importance of managerial skills. American Educational Research Journal, 48(5), 1091-1123.

Gronn, P. (1983). Talk as the work: The accomplishment of school administration. Administrative Science Quarterly, 28(1), 1-21.

Hallett, T., Harger, B., \& Eder, D. (2009). Gossip at work: Unsanctioned evaluative talk in formal school meetings. Journal of Contemporary Ethnography, 38(5), 584-618. 
Hallinger, P. (2005). Instructional leadership and the school principal: A passing fancy that refuses to fade away. Leadership and Policy in Schools, 4(3), 221-239.

Heracleous, L., \& Barrett, M. (2001). Organizational change as discourse: Communicative actions and deep structures in the context of information technology implementation. The Academy of Management Journal, 44(4), 755-778.

Horng, E. L., Klasik, D., \& Loeb, S. (2010). Principal's time use and school effectiveness. American Journal of Education, 116(4), 491-523.

Khalifa, M. (2012). A re-new-ed paradigm in successful Urban School leadership principal as community leader. Educational Administration Quarterly, 48(3), 424-467.

Klar, H. W., \& Brewer, C. A. (2013). Successful leadership in high-needs schools: An examination of core leadership practices enacted in challenging contexts. Educational Administration Quarterly, 49(5), 768-808.

Kraft, M. A., \& Gilmour, A. F. (2016). Can principals promote teacher development as evaluators? A case study of principals' views and experiences. Educational Administration Quarterly, 52(5), 711-753.

Leithwood, K., Harris, A., \& Hopkins, D. (2008). Seven strong claims about successful school leadership. School leadership and management, 28(1), 27-42.

Lortie, D. C. (2009). School principal: Managing in public. Chicago: University of Chicago Press.

Lowenhaupt, R. (2014). The language of leadership: Principal rhetoric in everyday practice. Journal of Educational Administration, 52(4), 446-468.

Lowenhaupt, R. \& McNeill, K. L. (2019). Making the case for K8 science supervision: Subjectspecific instructional leadership in an era of reform. Leadership and Policy in Schools, 18(3), 460-484. https://doi.org/10.1080/15700763.2018.1453937

Lowenhaupt, R., Spillane, J., \& Hallett, T. (2016). Accountability talk: Pulling down institutional logics in organizational practice. Journal of School Leadership, 26(5), 783-810.

Mehan, H. (1983). The role of language and the language of role in institutional decision making. Language in Society, 12(2), 187-211.

Mouton, N., Just, S. N., \& Gabrielsen, J. (2012). Creating organizational cultures: Re-conceptualizing the relations between rhetorical strategies and material practices. Journal of Organizational Change Management, 25(2), 315-331.

Peterson, K. D. (1977). The Principal's tasks. Administrator's Notebook, 26(8), 1-4.

Peterson, K. D., \& Kelley, C. (2002). Principal in-service programs. In M. S. Tucker \& J. B. Codding (Eds.), The principal challenge: Leading and managing schools in an era of accountability (pp. 313-333). San Francisco, CA: Jossey-Bass.

Rallis, S. F., \& Goldring, E. B. (2000). Principals of dynamic schools: Taking charge of change. Thousand Oaks, CA: Corwin Press.

Riehl, C. (1998). We gather together: Work, discourse, and constitutive social action in elementary school faculty meetings. Educational Administration Quarterly, 34(1), 91-125.

Riehl, C. J. (2000). The Principal's role in creating inclusive schools for diverse students: A review of normative, empirical, and critical literature on the practice of educational administration. Review of Educational Research, 70(1), 55-81.

Spillane, J. \& Lowenhaupt, R. (2019). Navigating the Principalship: Key insights for new and aspiring leaders. Alexandria, VA: ASCD.

Spillane, J. P. (2012). Distributed leadership (Vol. 4). San Francisco, CA: Wiley.

Spillane, J. P., \& Lee, L. C. (2014). Novice school principals' sense of ultimate responsibility: Problems of practice in transitioning to the principal's office. Educational Administration Quarterly, 50(3), 431-465.

Stone, D. A. (1997). Policy paradox: The art of political decision making. New York, NY: WW Norton.

Suddaby, R., \& Greenwood, R. (2005). Rhetorical strategies of legitimacy. Administrative Science Quarterly, 50(1), 35-67. 
Symon, G. (2005). Exploring resistance from a rhetorical perspective. Organization Studies, 26(11), 1641-1663.

Tashakkori, A., \& Teddlie, C. (Eds.). (2010). Sage handbook of mixed methods in social \& behavioral research. Thousand Oaks, CA: Sage.

Watson, T. J. (1995). Rhetoric, discourse and argument in organizational Sensemaking: A reflexive tale. Organization Studies, 16(5), 805-821.

Wolcott, H. (1973). The man in the principal's office: An ethnography. New York, NY: Holt, Rinehart and Winston.

Open Access This chapter is licensed under the terms of the Creative Commons Attribution 4.0 International License (http://creativecommons.org/licenses/by/4.0/), which permits use, sharing, adaptation, distribution and reproduction in any medium or format, as long as you give appropriate credit to the original author(s) and the source, provide a link to the Creative Commons license and indicate if changes were made.

The images or other third party material in this chapter are included in the chapter's Creative Commons license, unless indicated otherwise in a credit line to the material. If material is not included in the chapter's Creative Commons license and your intended use is not permitted by statutory regulation or exceeds the permitted use, you will need to obtain permission directly from the copyright holder.

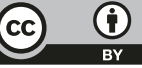

